\title{
The role of infill building in the sustainable conservation Casestudy : Surabaya downtown
}

\author{
Bambang Soemardiono ${ }^{a^{*}}$, Defry Agatha Ardianta ${ }^{a}$ \\ ${ }^{a}$ Institut Teknologi Sepuluh Nopember Surabaya, Indonesia \\ E-mail address: bamsoem03@yahoo.com; agathadefry@gmail.com
}

\begin{abstract}
Most of the building in the conservation area in Surabaya are facing such dillematic situation. One side the heritage buildings should keep the architectural, historical, aesthetical as well as social values but in the other side they must be developed based on the real market demand. Infill building should be the solution in making respectful contemporary contribution to the conservation area. The result of this paper is to formulate a framework requirements of the development and suggest the role in form of model of infill building based on the sustainable conservation approach, so the development is not only solving the physical problems but also non-physical.
\end{abstract}

Keywords: infill building; Surabaya downtown; sustainable conservation

\section{Introduction}

The Development of City Surabaya as the second largest City Indonesians is very rapid. This situation force the development of the new building in the commercial area, even in the conservation area such in downtown of Surabaya like Tunjungan and other location. Most of the building in the conservation area in Surabaya are facing such dillematic situation. One side the heritage buildings should keep the architectural, historical, aesthetical as well as social values but in the other side they must be developed based on the real market demand. Infill building should be the solution in making respectful contemporary contribution to the conservation area. The result of this paper is to formulate a framework requirements of the development and suggest a model of infill building based on the sustainable conservation approach, so the development is not only solving the physical problems but also nonphysical.
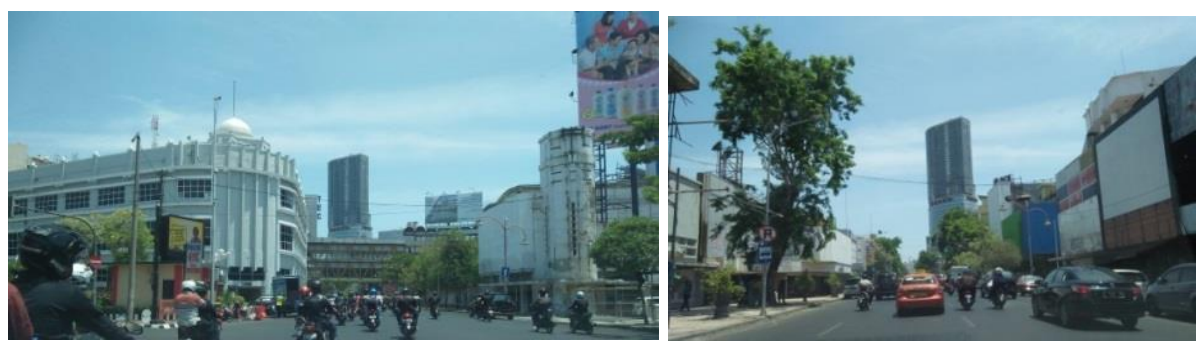

Fig. 1. and 2. Urban Conservation Area Tunjungan. (source : Researcher, 2016)

\section{Research Theories and Methods}

\subsection{Infill Building}

Infill is important issue. Many urban situations, new buildings will necessary be located next to building of heritage significance (Tanner, 1985). With care, new infill can complement the existing environment. The sucess of this endeavour depands on the scale of the development, the quality of the design and its capacity to assume the characteristic of the environment.Architectural good manners are essential to ensure that the building's height, scale, 
colour and use are not out of character with the surroundings. The key principles developed concerned the following building elements such as windows and doors, verandahs, planting, relation to neighbouring buildings, line of vision/skyline, architectural detail, wall and roof finishes, walls and fences, roof form as well as mass and scale.

The example of Infill building is Ripcurl in Adelaide's Rundle Mall which is between the conservation buildings named the landmark State Heritage Listed Adelaide Arcade and Regent Arcade buildings, the former Regent Cinema laneway. The concept of infill building is to respect the heritage of the place by designing contribution of contemporary approach, as follows:

The new buildings transparency and volume allows the conserved and featured adjoining heritage walls to form an intrinsic part of the new building space with dramatic and elegant effect. The Ripcurl building represents a departure from the typical retail shopfront / window display approach. Through its transparency it commands a more intense visual interaction between pedestrians and its internal retail functions.

The important is, that there is a challenge on designing the new building which is eye catching and contemporer, just not only have commercial aspect both for the owner and the tenant, but also respect with the significancy of the heritage buildings, The solution of the design is 12 meter high atrium space that relate or compatible with the other's the building height and the light to the entry of atrium showing the transparancy of the new building and the lightness of structure. The interesting are all connections onto the adjoining heritage walls are made of glass including the roof connections. The minimal structural steel frame are neutral, independent from historic the buildig facade as well as showing the lightness and the transparency of the new structure against the historic masonry walls.

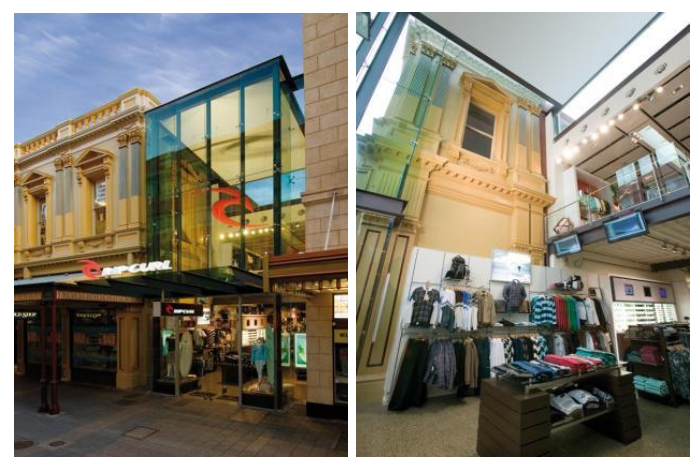

Fig. 3. Ripcurl in Adelaide's Rundle Mall.

\subsection{Conservation and Sustainable Conservation}

The Burra Charter 2000 describe that to establish the cultural significance which has been declared in illustrated Burra Charter 1992 consist not also aesthetic-, historical-, scientific- but also social value. The criteria added are rarity, ability to demonstrate typicality and the capacity to educate. In other hand the Burra Charter suggest the approach in changing mainly to maintain the place and make it useful, but changing less in keeping the significance of the culture (English Heritage, 2008). Based on (Rietdorf, 1989) there are different approaches in renewing of a city:

a) new use through compatibility which is the existing use will be srongth developed or kept as the existing ones and the existing building will be kept and may the new standards would be suited

b) new use through new building which is the existing use stands in the previous land or in the buildingsenvelope

Sustainable conservation needs the human factor to be considered in the development. It is important that human culture, local values connected with the outcomes of conservation 


\subsection{General Design Criteria and Concept:}

Universal guidelines for creating additions to heritage building are as follows (English Heritage, 2008):

a) Recessing the addition back from the historic structure

b) Compatibility of materials, including color and texture

c) Compatibility of scale, size and form/shape

d) Proportional relationship between openings and compatible proportion of solid to void

e) Continuity of horizontal such as cornices, string courses and plinths

f) The new addition will not disadvantage the heritage building by its aesthetic unsuitability

Infill Building should represent the succesfully collaboration between the new elements with in the old construction of conservation or heritage building through revitalization. From the different sources such as Models and Guidelines for Infill Development described the component of successfull strategy infill as follows

a) The infill building should well planned in order to suit with the existing building

b) The regulation and information should be clear in understanding the previous function of the existing heritage area. Consistency of regulation should be considered in making the heritage area and the image of area in managing infill area and

c) The participation of the community support the successfull infill building

d) Infill should accomodate the connectivity between sourrounding area such as streetscape , open space and transportation. Circulation and access are needed in keeping transportation strategy between infill building area and circulationnsystem sourrounding

e) Compatibility should be the main element in deciding infill strategy of conservation building or area.

Downtown Heritage Character Zone Design Guidelines described that in keeping the identity

a) The city must have regulation regarding the heritage area.

b) Character should be keep in order not to loose the identity and to gain harmony with suitability with the sorrounding area

c) Building character should be kept by considering the architectural- , the quality- as well as the potency of building

d) The characteristic and uniqueness aspect of building

e) The facade and element of heritage building.

f) The heights and material of infill building should be adjusted with the building in sorrounding as well as The border line of the horizontal and vertical vertical

Other reference) shows that the best infill shoud consider character, scale, form, site, colour/material and detail (Martokusumo, 2003). And urban heritage conservation and revitalisation the following aspects must be taken into account:

a) understanding the subject and the process of urban conservation

b) objectives of urban conservation

c) socio-ecological orientation

d) co-operation instead of confrontation in planning process.

The idea of programming as an effort to maximize knowledge about the figural concepts of design may be seen in Donna Duerk's Architectural Programming, a text with the subtitle Information Management for Design.Besides, Duerk incorporate the three phases of the systematic model of design process with two additional components as follows, the performance objectives of eventual design and concepts design ideas that develop from the synthesis activities. 


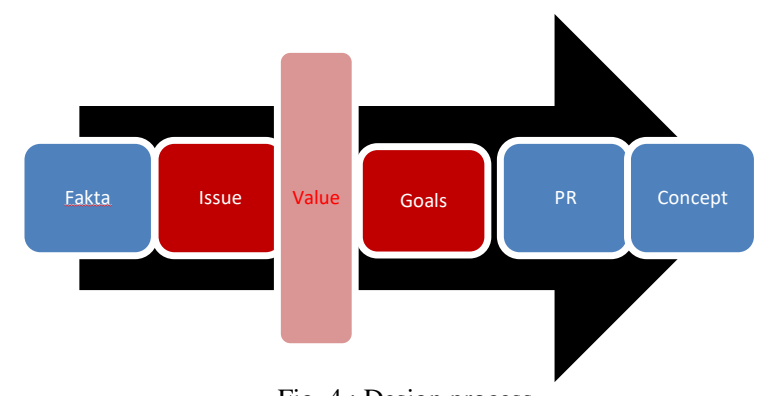

Fig. 4 : Design process.

(Duerk, D.P.(1998). Architectural Programming)

\section{Result and Discussion}

From the general design criteria it can be summarized the design framework that suitable to be applied in case Surabaya's heritage building such as:

a) Infill building must represent the succesfully collaboration and compatibility (the height and material ) between the new elements (facades) within the old construction of conservation or heritage building in order to gain harmony with the existing building and deciding infill strategy of conservation building area

b) The regulation and information regarding the heritage building must be clear in understanding the previous function of the existing heritage area

c) The participation of the community in planning process must be important in supporting the successfull of infill building design

d) Infill should accomodate the connectivity between sourrounding area such as streetscape , open space and transportation.

e) Building character should be kept by considering the architectural- , the quality- as well as the potency of building

\subsection{Building in Bubutan Street}

a) Bubutan is wellknown as downtown area of old building such as Gedung Nasional Indonesia, old office magazine Penjebar Semangat and Polsek Bubutan in the corner. Although fully with old several buildings and commercial area but it is not yet fully developed

b) This two floors square building and the colonial style house located on the downtown Bubutan Street and recently are empty. These buildings has two facades front and rear facade (faceted corner) and the building has not the same height with other building. The character of the facade of housing is unique and predicted that was a veranda which is now covered by glassfacade
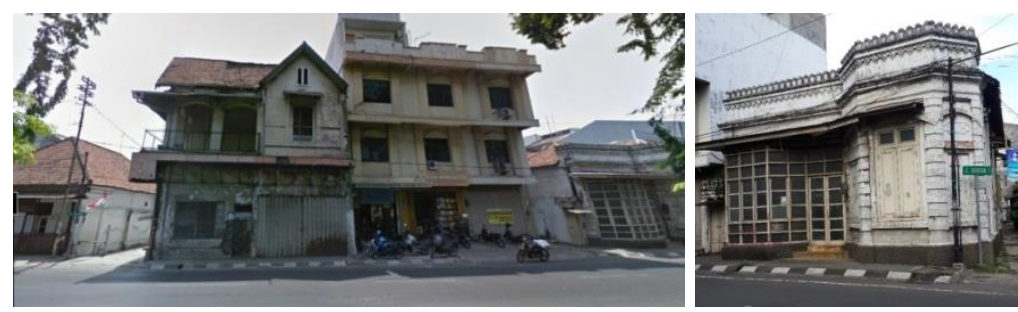


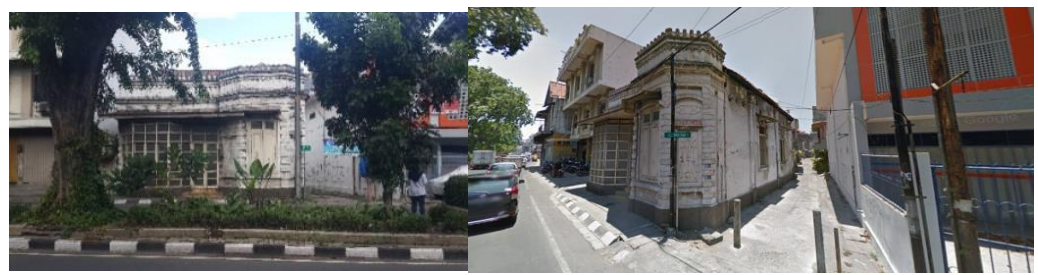

Fig. 5. The existing old Buildings in Bubutan.

\begin{tabular}{|l|l|c|}
\hline \multicolumn{1}{|c|}{ Design Criteria } & \multicolumn{1}{c|}{ Concept Design } \\
\hline $\begin{array}{l}\text { 1. Collaboration and } \\
\text { compatibility } \\
\text { 2articipation of the } \\
\text { community } \\
\text { Connectivity between } \\
\begin{array}{l}\text { Sourrounding. } \\
\text { Keeping the building } \\
\text { character }\end{array}\end{array}$ & $\begin{array}{l}\text { Infill Building as solution in making the development without } \\
\text { major changes in the original building such keeping th original } \\
\text { facade and added a new glass on the front facade connecting the } \\
\text { different character of sorrounding. }\end{array}$ \\
\hline
\end{tabular}

\subsection{Sakura Building : Shophouse at Rajawali -Branjangan Street}

a) This corner building was an old photo studio building. As a corner building in commercial area, Sakura Building has important aspect to be developed compared to the other buildings.

b) This old building located in the strategic downtown of North Surabaya. It has doric columns, precisly at the corner of Rajawali street and near the historical bridge Jembatan Merah,

c) Surrounded by heritage buildings as well as closed to the large scale commercial and services

d) The neighourhood building has already revitalized with recently use and suit to the character of area 


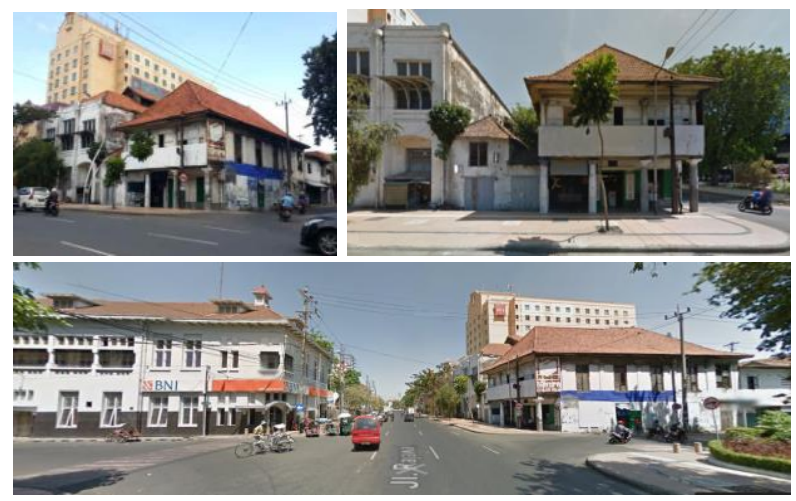

Fig. 8. Shophouse Building at Rajawali - Branjangan Street. (Researcher \& Google )

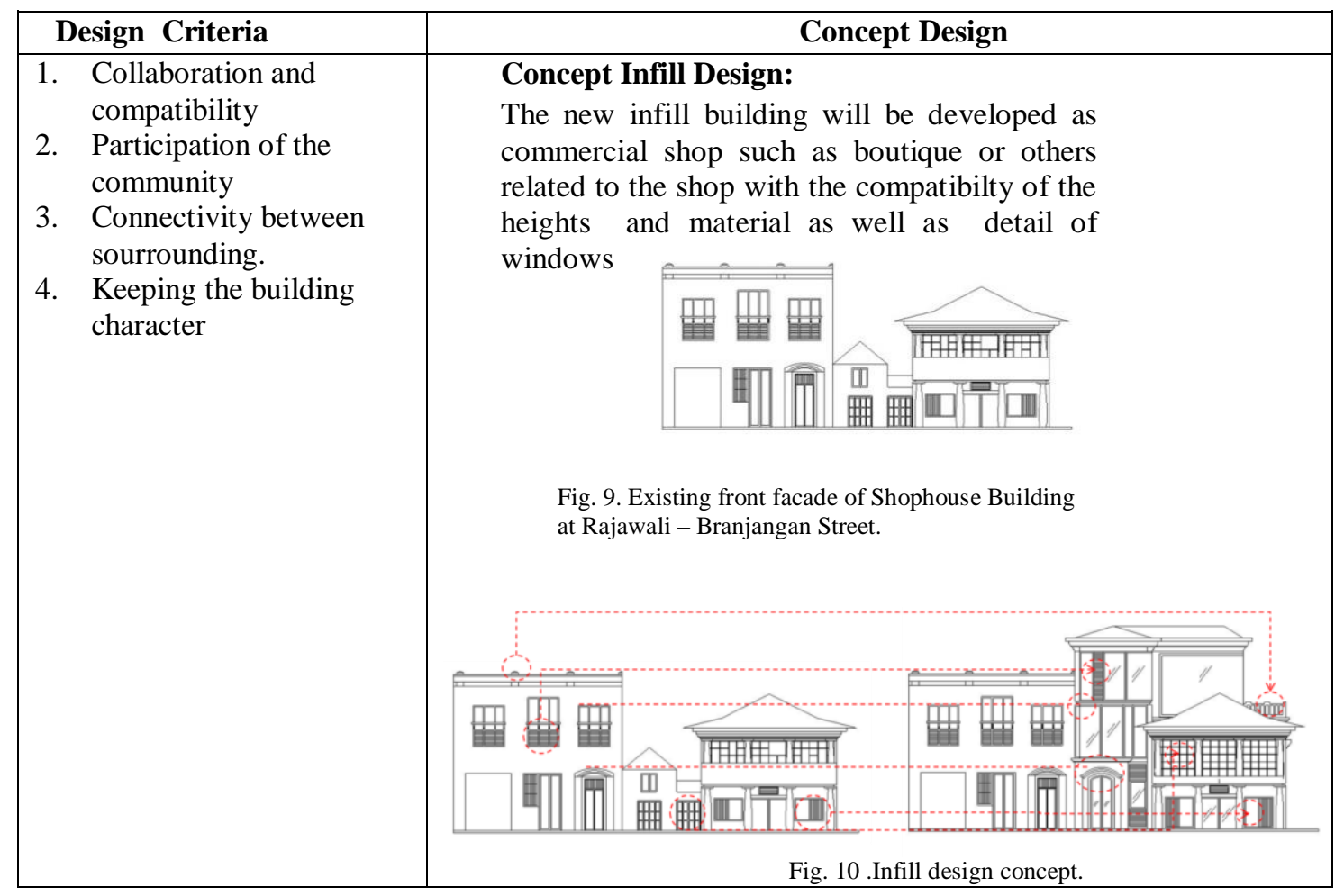

\section{3 .Mandiri Bank}

a) This Building has a very high value in architectural aspect and is recently used for bank

b) As a corner building in the crosssection between Rajawali Street and Jembatan Merah. The rear facade seems have special treatment, which the function as well as expression showed by detail in windows and glass 


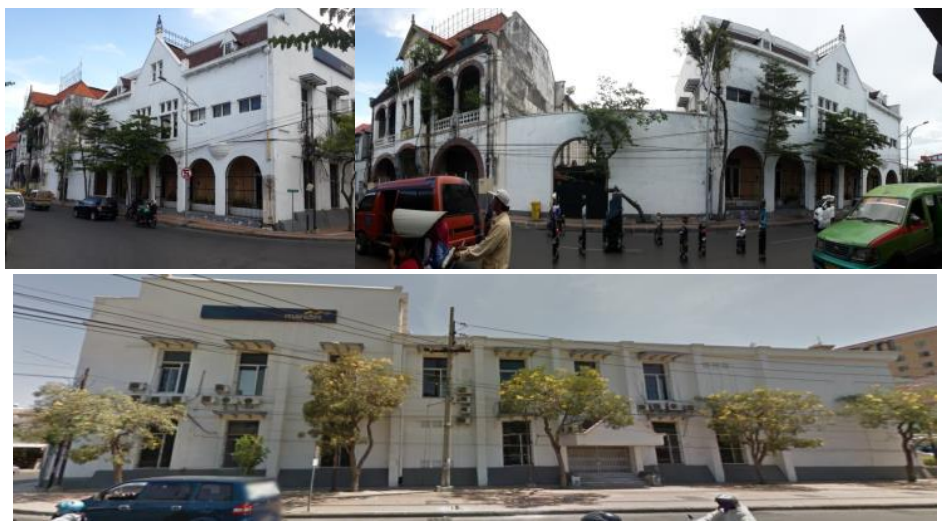

Fig. 11. Mandiri Building.

(Researcher, 2016 and Google Earth )

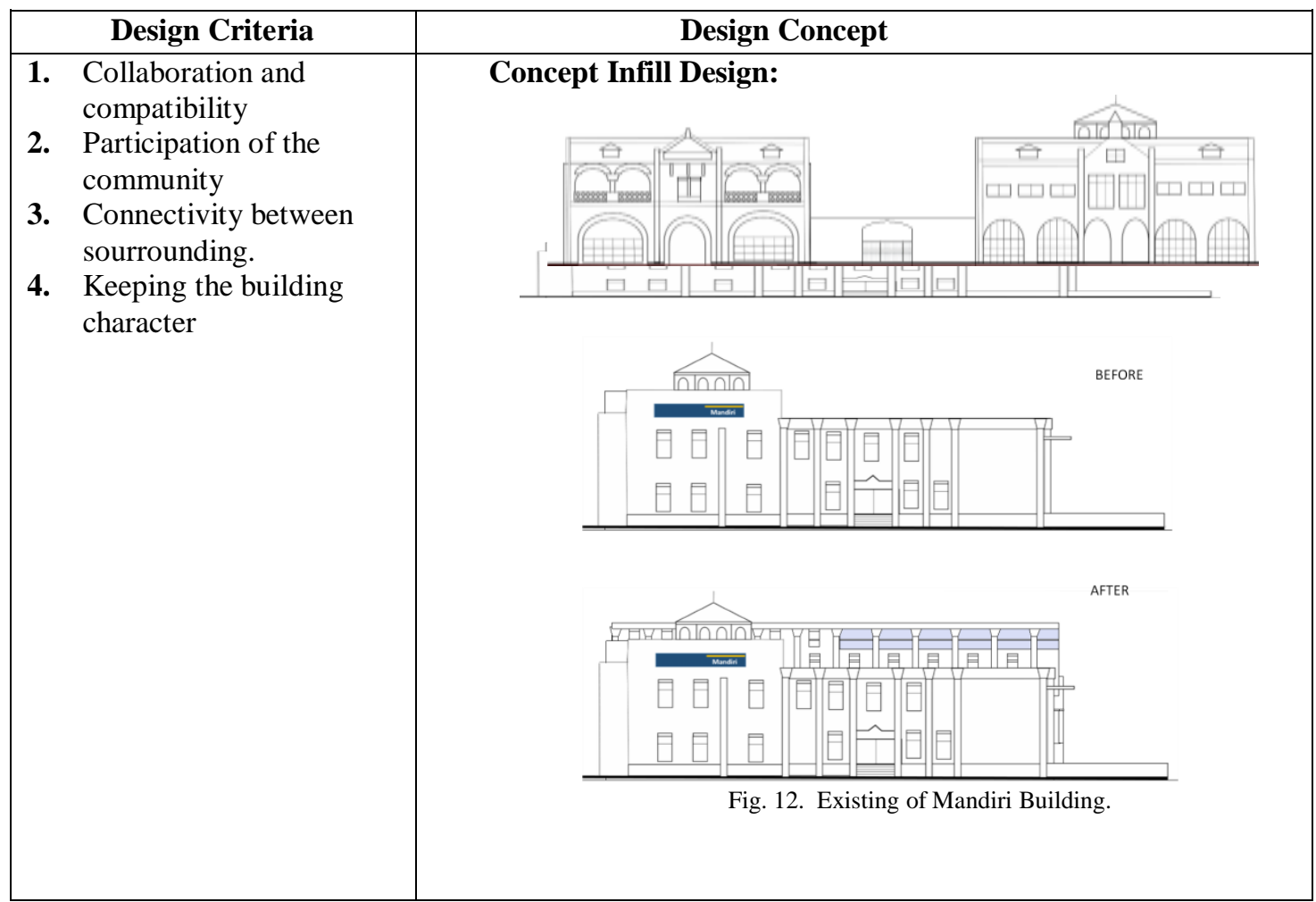




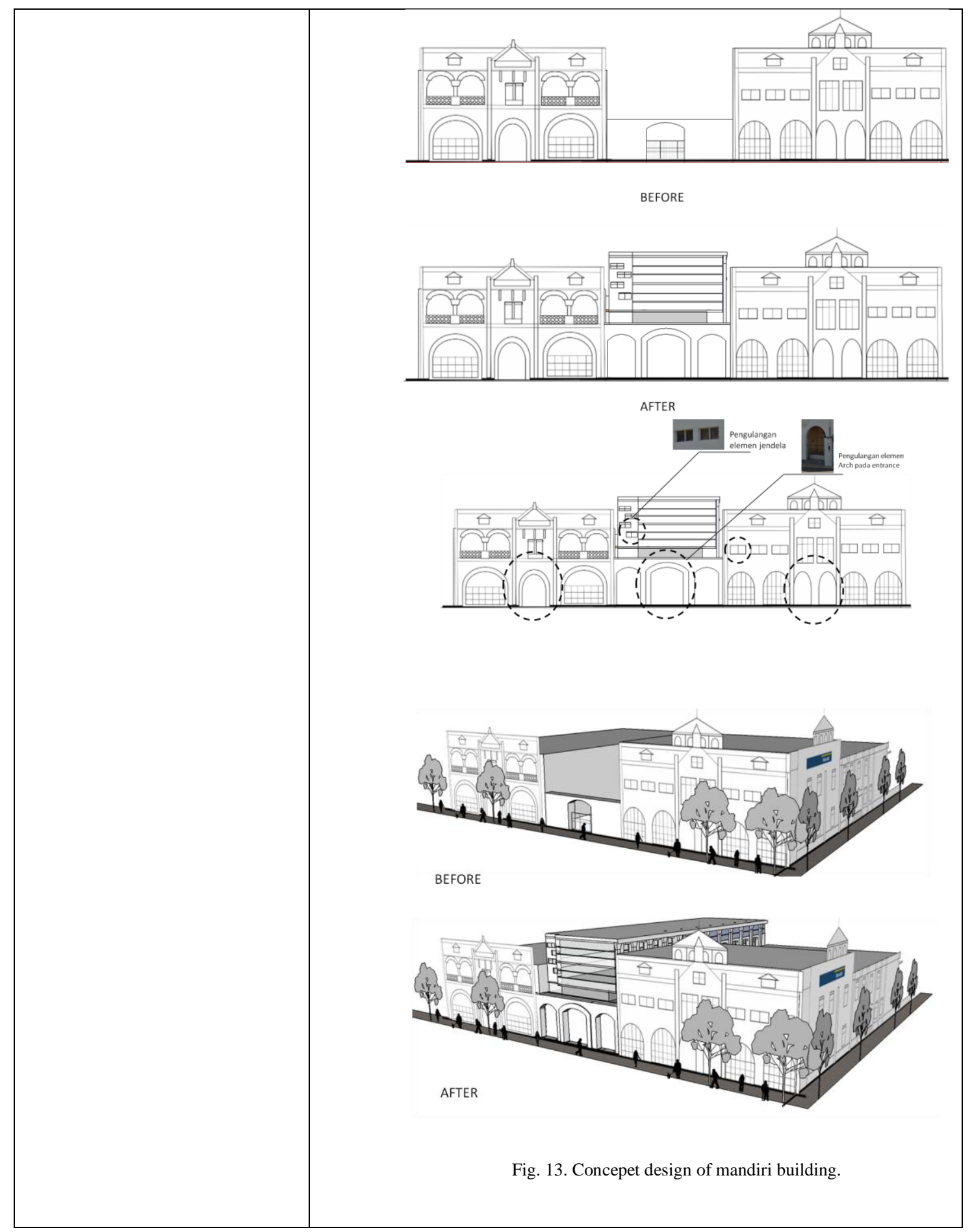




\section{4 .Saver Mulia Building}

Saver Mulia Building is a corner building across Tunjungan and Genteng Besar. This design of the building although look simple and modern but lacking in the character of the context of a building in the conservation area.
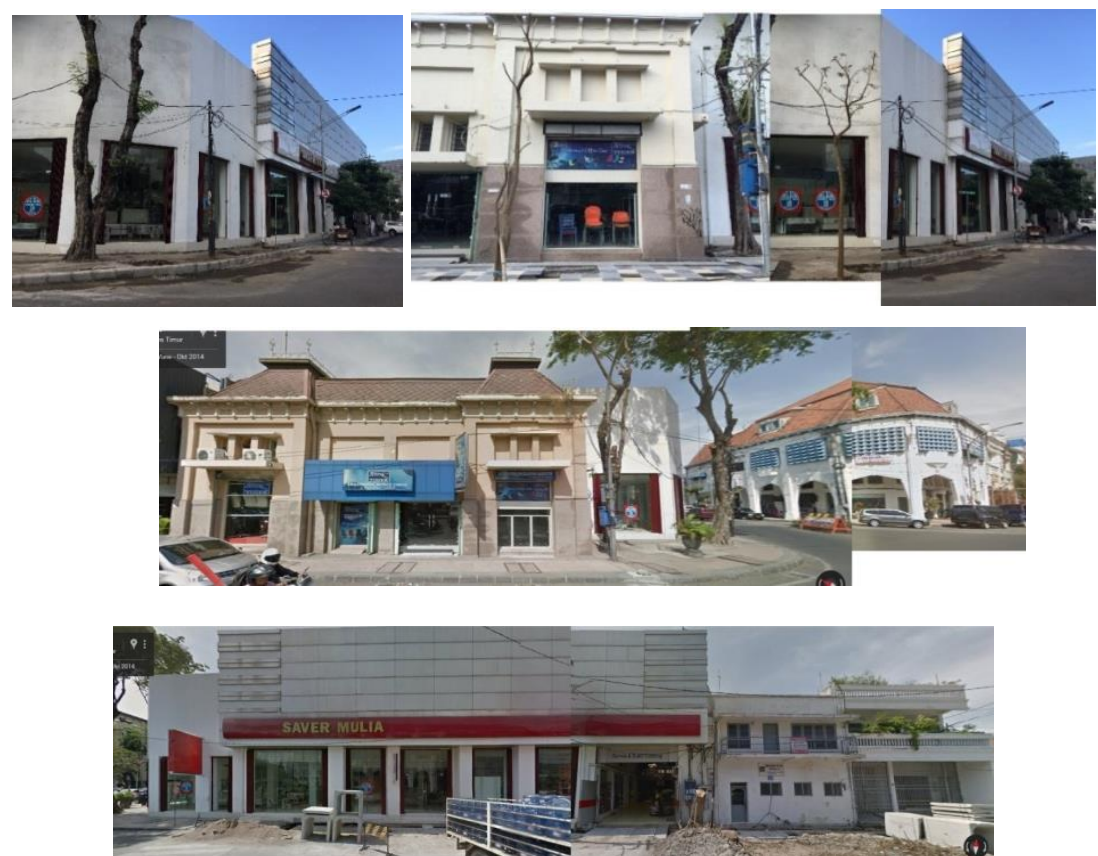

Fig. 14. Saver Mulia Building.

(Researcher, 2016 and Google Earth )

\begin{tabular}{|l|l|}
\hline \multicolumn{1}{|c|}{ Design Criteria } & \multicolumn{1}{|c|}{ Concept Design } \\
\hline $\begin{array}{l}\text { Collaboration and } \\
\text { compatibility } \\
\text { Participation of the } \\
\text { community } \\
\text { Connectivity between } \\
\text { Sourrounding. } \\
\text { Keeping the building } \\
\text { character }\end{array}$ & $\begin{array}{l}\text { Concept Infill Design } \\
\text { Repetition of vertical element and element of the windows } \\
\text { colonial building and designing the facade inspired by the } \\
\text { conservation building }\end{array}$
\end{tabular}




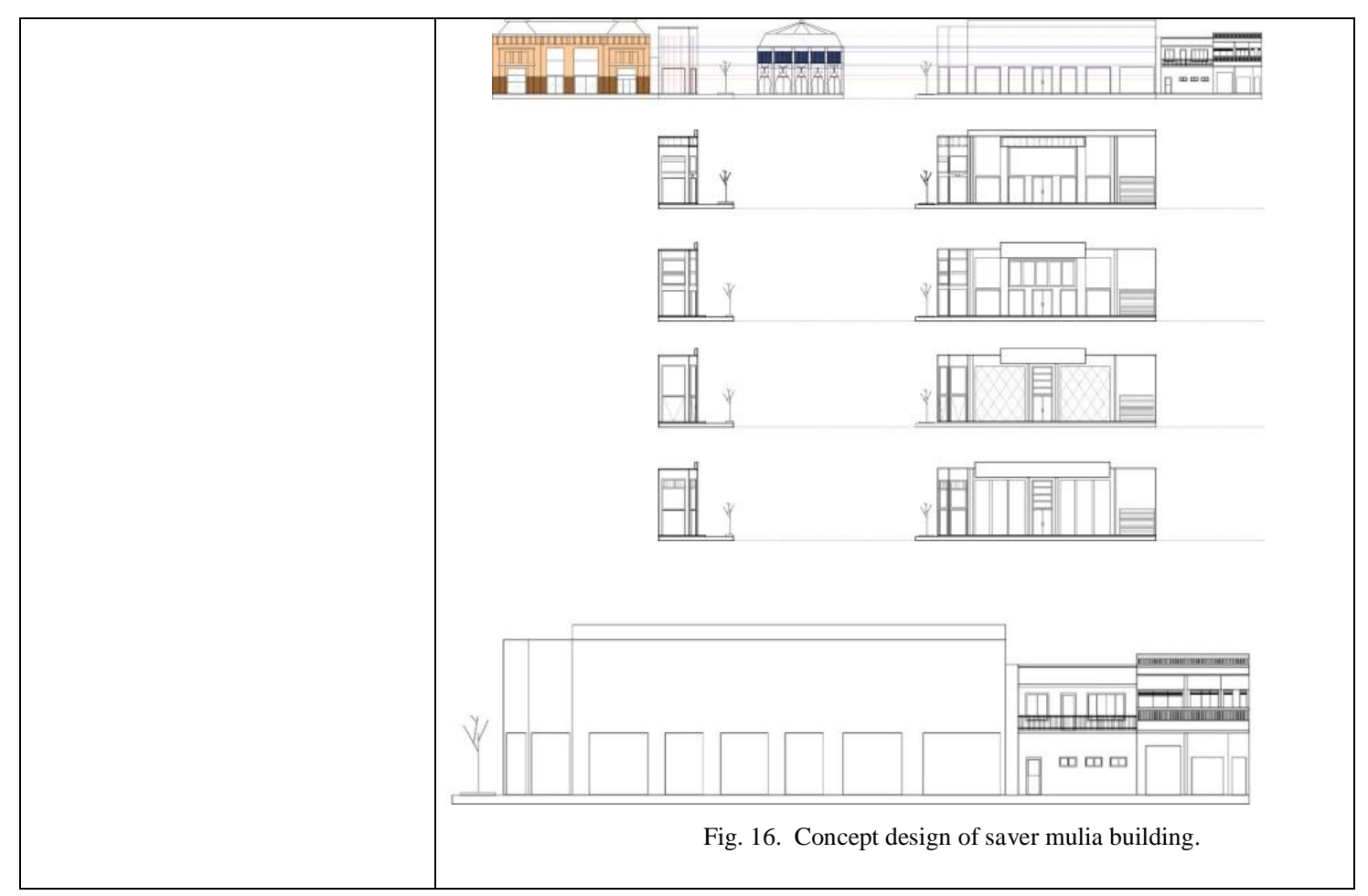

\section{Conclusion}

The result of this paper are the role of Infill Building in form of different models based on conservation approach, which consider the physical problems such as the economical and environmantal aspect but also nonphysical such as local value. The aspects of design framework that suitable to be applied in case Surabaya's heritage building such as succesfully collaboration and compatibility between the new elements (facades) within the old, clearly regulation and information regarding the heritage building, the participation of the community in planning process and connectivity between sourrounding area ans well as the building character which kept by considering the architectural-, the quality- as well as the potency of building

\section{References}

English Heritage. (2008). Conservation Principles, Policies and Guidance. London: English Heritage.

Martokusumo, W. (2003). THE ROLE OF URBAN CONSERVATION AND THE DISCOURSE ON MODERNISATION IN INDONESIA CASE: JAKARTA KOTA. In International Symposium and Workshop on "Managing Heritage Environment in Asia", Centre for Heritage Conservation. Yogyakarta.

Rietdorf, W. (1989). Stadterneuerung: innerstädtisches Bauen als Einheit von Erhaltung und Umgestaltung, mit 168 Zeichnungen und 343 Fotos. Verlag für Bauwesen.

Tanner, H. (1985). Building conservation and infill. In P. Freeman, E. J. Martin, J. Dean, \& R. A. I. of Architects (Eds.), Building conservation in Australia (pp. 42-45). Canberra: RAIA Education Division. 